\title{
Bilgi Toplama ile Reklam Şüpheciliği Arasındaki İlişki: Yetkisiz İkincil Bilgi Kullanımı ve Ürün Kalitesinin Seri Aracilık Rolü
}

\section{The Relationship Between Information Collection and Ad Skepticism: Serial Mediating Role of Unauthorized Secondary Use and Product/ Service Quality}

\author{
Erkan YILDIZ, Başkent Üniversitesi, Türkiye, eyildiz@baskent.edu.tr \\ Orcid No: 0000-0002-4398-5378 \\ Çağla Pınar BOZOKLU, Başkent Üniversitesi, Türkiye, cutkutug @ hotmail.com \\ Orcid No: 0000-0002-4147-9519
}

\begin{abstract}
Öz: Bilgi gizliliği konusu, bilgi toplamanın ve yetkisiz ikincil bilgi kullanımın slkça karșılașıldı̆̆ı günümüzde en önemli ticari etik sorunlardan biri haline gelmiştir. Bilgi gizliliği, kişinin kendi hakkindaki bilgilerini bireysel olarak kontrol edebilme yeteneğidir. Bu araştırmanın amact ise, genç tüketiciler açısından bilgi toplama ile reklam süpheciliği arasındaki ilişkinin ve bu iliski kapsamında vetkisiz ikincil bilgi kullanımı ve ürün kalitesi algısının seri aracılık etkisini test etmektir. Araş̧tırma kapsaminda, internet ve basll form üzerinden 1157 anket doldurulmuştur. Katıllmcılara kolayda ve kartopu örnekleme yöntemleri ile ulaşılmıştır. Araştırma örneklemi, çoğunlukla 18-25 yaş aralığında en düşük üniversite eğitimi olan genç tüketiciler olarak belirlenmistir. Araștırma modelinin analiz edilmesinde kismi en küçük kareler yol analizi (PLS-SEM) kullanılmıștır. Veriler SmartPLS 3.2.8 istatistik programı kullanılarak analiz edilmiştir. Modele ait elde edilen $R 2$ değerleri incelendiğinde de yetkisiz ikincil kullanımın \%6, ürün kalitesinin $\% 4$ ve reklam süpheciliğinin de \%12 oranında açıklandığ tespit edilmistir. Yapılan model testi sonucunda, bilgi toplamanın bu toplanan bilgilerin yetkisiz ikincil kullanımına yönelik kaygıları kuvvetlendirdiği tespit edilmiştir. Bilgi toplama ile reklam şüpheciliği arasındaki ilişkide bilginin yetkisiz ikincil kullanımına yönelik kaygıların da reklam şüpheciliğini tetiklediği, ancak ürün kalitesi algısının yüksek olması nedeniyle bu etkinin bastırıldı̆̆g ortaya koyulmuștur.
\end{abstract}

Anahtar Sözcükler: Bilgi Toplama, Yetkisiz İkincil Bilgi Kullanımı, Ürün kalitesi, Reklam şüpheciliği, Bankacılık, Smart PLS

\begin{abstract}
Nowadays, information privacy concept has become one of the most important problem in terms of business ethics. Information privacy is the ability of a person to control over her/ his personal information. The aim of this research is to test the relationship between information collection and ad skepticism with the serial mediating role of unauthorized secondary use of information and product/service quality. In the research, 1157 participants were reached through the online and the paper-pen questionnaires by convenient and snowball sampling methods. The research sample was mostly composed of the young consumers (age between 18-25) with the university diploma at least. SEM's Partial Least Squares (PLS-SEM) approach is carried out for the test of the research model by using Smart PLS 3.2.8 statistic program. According to R2 values, unauthorized secondary use of information, product/ service quality and ad skepticism were explained as $6 \%, 4 \%$ and $12 \%$ respectively. After the model test, it is ascertained that information collection enhances the concerns about unauthorized secondary use of it. In the relationship between information collection and ad skepticism, unauthorized secondary use of information triggers the ad skepticism although this effect is suppressed by the high quality perception of the products/ services.
\end{abstract}

Keywords: Information Collection, Unauthorized Secondary Use, Product/ Service Quality, Ad Skepticism, Banking, Smart PLS

\section{Giriş}

Son yıllarda yapılan araştırmalar, dünya üzerinde birçok bölgede, özellikle gençler arasında toplumsal güven algısının zayıfladığını işaret etmektedir (Pew Research Center, 2007; Rahn ve Transue, 1998). Bu güvensizlik eğiliminin en büyük nedeni olarak internetin gelişimi görülmektedir. Fiziksel etkileşime dayanan geleneksel kanallar yerine dijital kanallar aracılığı ile ilişkilerin ve işlemlerin yürütülmesi, tüketicilerin kişisel ve finansal bilgilerini paylaşmasını zorunlu kılmakta (Casaló, Flavián ve Guinalíu, 2007) ve dolayısıyla katlandıkları belirsizlik (Harris and Goode, 2004) ve riskin artmasına neden olmaktadır. Bu nedenle birçok yazar, gizliliğin güven açısından temel şartlardan biri olduğunu savunmaktadır (ör. Kruck vd., 2002; Flavia'n ve Guinalı'u, 2006).

Bu bağlamda bilgi gizliliği, kişinin kendi hakkındaki bilgilerini bireysel olarak kontrol edebilme yeteneğidir (Stone vd., 1983). Mason (1986), Smith (1994) gibi yazarlar 2000li yıllara gelmeden bilgi çağının en önemli etik sorunlarından birinin bilgi gizliliği olacağını öngörmüştür. Schlosser vd. (2006) ise, tüketici güvenindeki azalmanın özellikle ticari ilişkileri ve çevrimiçi yapılan işlemleri olumsuz etkileyeceğini belirtmiştir. Her ne kadar gizlilik üzerine araştırmalar ilk olarak 196011 yıllarda başlamış olsa da (ör. HEW, 1973; PPSC, 1977; Westin, 1967; Westin ve Baker, 1972); dijitalleşmenin getirdiği çı̆̆ır aşıcı yeniliklerin olduğu 19901 yıllarda (ör. Culnan, 1993; Milberg, vd., 1995; Smith, 1994;

Makale Gecmiși / Article History

Başvuru Tarihi / Date of Application : 30 Eylül / September 2019

Kabul Tarihi / Acceptance Date

: 20 Ekim / October 2019 
Stone, vd., 1983) ve 2000li yıllarda (ör. Milberg vd., 2000; Kruck vd., 2002; Stewart ve Segars, 2002; Malhorta vd., 2004; Flavia'n ve Guinalı'u, 2006; Casaló vd., 2007; Boush vd., 2009; Li ve Xu, 2010; Xu vd., 2011; Schwaig vd., 2013; Li, 2014) tekrar ilgi odağı olmuştur. Malhorta vd.'nin (2004) de ifade ettiği gibi, pazarlama çevresindeki değişiklikler bilgi gizliliği üzerine endişeleri, bu husus odaklı eğilimleri ve tutumları etkilemektedir. Günümüzde, sosyal medya tabanlı ve yapay zekâ içerikli uygulamalar, internet deneyimini farklı bir boyuta taşımıştır. Ancak bu gelişmeler, aynı zamanda kişisel bilgilerin erişilebilirliğini geçen yıllara göre daha da kolaylaştırmıştır. Örneğin, 2018 yılında ABD Federal Ticaret Komisyonu, "Cambridge Analytica" adlı veri analiz firmasının 50 milyon Facebook kullanıcısının verilerini hesaplarından izinsiz toplayıp, usulsüz olarak kullanması sonucunda Facebook’a soruşturma başlatmıştır (Hürriyet, 2018).

Bilgi gizliliği kavramı bankacılık hizmetlerine yönelik yürütülen bir çok araştırmada kullanılmıştır ( Oly Ndubisi ve Sinti, 2006; Pikkarainen vd., 2004; Wang vd., 2003; Ramayah ve Ling, 2002; Casalo vd., 2007). Pikkarainen vd. (2004), çoğu banka müşterisinin kişisel bilgilerin üçüncü bir tarafa (bir başka işletmeye) transfer edilmesinden ve bu durumu kontrol edemeyeceklerinden endişelendiği için, telefon ya da internet üzerinden bilgi paylaşmaktan kaçındığını ifade etmiştir. Casalo vd. (2007), bankacılık hizmetlerinde web sitesinin sunduğu güvenlik ve gizliliğin, kullanım kolaylığının ve itibarın müşteri güveni üzerinde doğrudan etkisini tespit etmiştir.

$\mathrm{Bu}$ araştırmanın amacı ise, genç tüketiciler açısından bilgi toplama ile reklam şüpheciliği arasındaki ilişkinin ve bu ilişki kapsamında yetkisiz ikincil bilgi kullanımı ve ürün kalitesi algısının seri aracılık etkisini test etmektir. Bu amaç doğrultusunda, öncelikli olarak bilgi gizliliği kavramı açıklandıktan sonra, bilgi toplama, yetkisiz ikincil bilgi kullanımı, ürün kalitesi ve reklam şüpheciliği arasındaki doğrudan ve dolaylı ilişkiler ele alınmaktadır. Literatürü takiben, araştırma yöntemi ve bulgular sunularak, araştırma sonuçları öneriler ile birlikte tartışılmaktadır.

\section{Bilgi Gizliliği Kavramı}

Gizlilik eğilimi, bir kişinin gizliliğe ilişkin genel tutumunu ifade etmektedir (Li vd., 2010; Xu vd., 2010; Li, 2014). Gizliliğe yönelik endişeler sektörel özellikler, toplumsal kültür, düzenleyici yasalar gibi birçok dış etmenden olduğu kadar, kişilik özellikleri ve geçmiş deneyimler gibi iç etmenlerden de etkilenebilmektedir (Donaldson ve Dunfee 1994).

Westin'in (1967, 2003), Altman'ın (1976) ve Laufer ve Wolfe'un (1977) geliştirdiği teoriler bu alanda en sik kullanılan çerçeveleri ortaya koymaktadır. Westin'in (2003) teorisine göre gizlilik kavramı için en önemli olgular bireylerin kişisel bilgilerinin ne zaman, nasıl ve ne bağlamda başkaları ile paylaşılacağıdır. Altman (1976), Westin'in (2003) teorisine benzer olarak, gizlilik kavramını bir kontrol mekanizması olarak ele alsa da; gizliliğin kişiler ve gruplar arasındaki bağlantılarla ilişsili kişilerarası durum olarak ele almaktadır. Laufer ve Wolfe (1977) ise bazı insanların bilgiye erişememesi durumunda, bilginin kontrol edilmesine yönelik girişimlerin söz konusu olabileceğini öne sürmüştür. Açıklanmamış veya gizli tutulmuş bilgilerin neden olacağı bilinçli ve bilinçsiz korkuların kişiliğe ve toplumsal yapıya özgü olması nedeniyle, gizliliğin korunması gerektiğini savunmuştur.

Özellikle çevrimiçi işlemler sırasında verilerin nasıl toplandığ yayılan tüketici güvensizliği, e-ticaretin yaygınlaşmasının önünde önemli bir engel olarak görülmektedir (Furnell ve Karweni, 1999; Flavia'n ve Guinalı'u, 2006). Çevrim içi ortam, tüketici bilgilerini rızaları olmaksızın toplayan teknolojilerin varlığı nedeniyle kişisel gizliliğin korunmasını zorlaştırmaktadır (Sai, 2008). Buna ek olarak, bazı çevrimiçi faaliyet gösteren firmalar bu bilgileri yasal olmadan elde edebilmekte ve ikincil amaçlarla kullanabilmektedir (Milberg vd., 2000). Bir diğer yandan, kişisel bilgilerin adil veya sorumlu bir şekilde kullanılmaması, temelde iki tür bilgi gizliliği endişesi doğurabilir. İlk olarak, bir güvenlik ihlali veya uygun denetimin olmaması nedeniyle kişisel bilgilere yetkisiz erişim sağlanırsa, bir kişinin mahremiyeti istila edilebilir. İkinci olarak, dijital bilgiler kolayca çoğaltılabildiğinden ve paylaşılabildiğinden dolayı ikincil kullanım riski taşırlar. Belirli bir amaç için toplanan bilgiler, kişinin bilgisi veya izni olmadan ilgisiz amaçlar için tekrar kullanılabilir (Culnan 1993, Foxman ve Kilcoyne 1993, Goodwin 1991, Smith vd. 1996; Wang vd., 1998; Culnan ve Armstrong, 1999). Bu nedenle:

H1: Bankacılık hizmetleri kapsamında genç tüketicilerin kişisel bilgi toplamaya yönelik algılarının, bu bilgilerin yetkisiz ikincil bilgi kullanımına yönelik endişeleri üzerinde doğrudan etkisi vardır.

\subsection{Bilgi Toplama ve Yetkisiz İkincil Bilgi Kullanımının Ürün/Hizmet Kalitesi ve Reklam Şüpheciliği Üzerindeki Etkisi}

Smith vd. (1996), bilgi gizliliği kavramını işletmelerin uygulamalarına yönelik bireysel endişeler düzeyinde ele almış ve birden fazla boyut aracılığı ile bilgi gizliliğini açıklayan bir ölçek geliştirebilmek için kapsamlı bir literatür taraması yapmıştır. İçerik analizi aracılığı ile federal yasalara ve yasal tutanaklara ek olarak, 1983- 1990 arasında Privacy Journal (Gizlilik Dergisi) isimli dergide yayınlanmış 960 makaleyi analiz etmiştir. Bu analiz sonucunda en çok kişisel bilginin toplanması, kişisel bilginin yetkilendirilmeksizin içeriden ikincil kullanımı, kişisel bilginin yetkilendirilmeksizin dişardan ikincil kullanımı, kişisel bilgilerde hata ve kişisel bilgilere usulsüz erişim boyutlarının kullanıldığını tespit etmiştir.

Toplama, Miller'ın (1982: 96) da ifade ettiği gibi toplum genelinde çok fazla veri toplanmasına yönelik endişeleri yansıtmaktadır. Kişiler sıklıkla kendileri, geçmişleri ve eylemleri hakkında toplanan devasa ölçekli bilgilerin farkındadırlar ve bu durum onları içten içe sinirlendirir (Milberg vd., 2000).

Yetkisiz ikincil kullanım ise, kişilerden belirli bir amaç doğrultusunda onay dahilinde temin edilmiş bilginin başka bir amaç doğrultusunda yetkisiz kullanımını ifade etmektedir. Yetkisiz ikincil kullanım, aynı işletme içerisinde olabildiği gibi, farklı bir işletmeyle paylaşılmak suretiyle üçüncü bir tarafın araya girmesiyle de söz konusu olabilir. Tolchinsky et al. (1981) bu bilgilerin özellikle ikinci bir işletmeyle yetki olmaksızın paylaşılmasının tüketicilerin gösterdiği negatif 
tepkileri şiddetlendirdiğini belirtmiştir. Milberg vd. (2000), bu kapsamda en çok örnek paylaşılan bilgiler olarak, tüketicilerin isim ve soyadına, telefon numarasına, adres kayıtlarına, satın alma geçmişlerine ve satın alınan ürün kategorilerine ait bilgiler olduğunu tespit etmiştir.

Hizmet kalitesi ise, e-ticaretin başarısını belirleyen temel etmenlerden biridir (Yang, 2001). Grönroos (1984: 37) ve Parasuraman vd. (1985:42) hizmet kalitesini tüketicinin hizmetten beklentisi ile karşılanma derecesi olarak tanımlamıştır. Grönroos (1984) hizmet kalitesini daha çok fonksiyonel /teknik kalite olarak ele alırken; Parasuraman vd. (1988) güvenilirlik, karşılanma süresi, empati gibi alt boyutlarla değerlendirmiştir. Buna uygun olarak Zeithaml vd. (2000), ehizmet kalitesini ölçmek için erişim, navigasyon kolaylığı, verimlilik, esneklik, güvenilirlik, kişiselleştirme, güvenlik/ gizlilik, cevap verme hızı, güvence/ güven, site estetiği ve fiyat bilgisi olmak üzere 11 alt boyuttan oluşan e-Servqual ölçeğini geliştirmiş̧ir. Bu ölçek, güvenlik ve gizlilik ile ilgili bilgi toplama ya da yetkisiz ikincil kullanım gibi öğelerin hizmet kalitesini doğrudan etkilediğini göstermektedir. Dolayısıyla:

H2: Bankacılık hizmetleri kapsamında genç tüketicilerin bilgi toplamaya yönelik algılarının, ürün kalite algısının üzerinde doğrudan etkisi vardır.

H3: Bankacılık hizmetleri kapsamında genç tüketicilerin yetkisiz ikincil bilgi kullanımına yönelik algılarının, ürün kalite algısı üzerinde doğrudan etkisi vardır.

Dijital gizlilik bildirimi, web sitelerinin uyması gereken olumlu yükümlülüklerden biridir (ör. California yasaları ve federal uygulamalar; bakınız Calo, 2011:1029). Buna göre, çevrimiçi hizmet sunan işletmeler gizlilik politikasına bağlıdır. $\mathrm{Bu}$ sayede tüketiciler, gizlilik politikalarını okuyup karşılaştırarak hangi hizmetleri kullanılacağına, hangilerini kullanmayacağına karar verebilmektedir (Cate, 2006). Zorunlu gizlilik bildirimleri çok popüler olmasına karşın; şüpheci kişiler tarafından yetersiz görülebilmektedir. Bu kişiler, bildirimleri az sayıda tüketicinin okuduğunu ve hatta onlardan daha azının anladığını; dolayısıyla kendilerini koruyabilecek veya pazarı denetleyebilecek bilinçli karar vericiler haline gelmediklerini savunmaktadır (Edwards, 2004). Günümüzde, markalar rekabetten biraz da olsa siyrılabilmek için, kişisel bilgilere dayalı tüketiciye özel reklam mesajları sunmaktadır. Hedefleme tekniği ismi verilen bu yöntem, reklam verenlerin reklam etkinliğini artırmalarının başarılı bir yolu olsa da, gizlilik endişelerinin körüklenmesine neden olmaktadır. Milne ve Boza (1999), Phelps vd. (2001), gizlilik endişelerinin reklam etkinliğine olumsuz etkilerini tespit etmiştir. Baskın görüş, gizlilik endişesinin reklama yönelik şüpheyi, reklamdan kaçınma ve reklam ile markaya karşı olumsuz tutumları artırdığı yönündedir (Baek ve Morimoto, 2012; Phelps et al., 2001; Smit vd.,2014). Tüketiciler kişiselleştirilmiş reklam mesajları ile karşılaştıklarında, birilerinin kendileri hakkında kişisel bilgilere sahip olduğunu ve bilgileri pazarlama amaçları doğrultusunda kullandığını anlamaktadır (Okazaki vd., 2009). Bu önsezi ise tüketicilerin reklam mesajına direnç göstermesine neden olmaktadır (Brehm ve Brehm, 1981; Knowles ve Linn, 2004; White vd., 2008). Buna bağlı olarak:

H4: Bankacılık hizmetleri kapsamında genç tüketicilerin bilgi toplamaya yönelik algılarının, reklama yönelik şüphe üzerinde doğrudan etkisi vardır.

H5: Bankacılık hizmetleri kapsamında genç tüketicilerin kişisel bilgilerin yetkisiz ikincil kullanımına yönelik algılarının, reklama yönelik şüphe üzerinde doğrudan etkisi vardır.

\section{2. Ürün/Hizmet Kalitesinin Reklama Yönelik Ş̈̈phe Üzerindeki Etkisi}

Kısaca reklam şüpheciliği kavramı, tüketicilerin reklamın bilgi sunma faaliyetine güvenmeme eğilimi olarak ifade edilebilir (Obermiller ve Spangenberg, 1998, Elving, 2013). Obermiller ve Spangenberg (1998: 59-186) reklama duyulan şüphenin bireyin şüphe eğilimi ile ilgili olduğunu belirtse de, şüphe seviyesinin arttırılmasında bilgi kaynağının önemini savunmaktadır. Reklama yönelik şüpheye odaklanan araştırmalar tüketicinin davranış ve özelliklerini temel alan araştırmalar (Boush vd. 1994: 311-322; Obermiller 1998: 159-186; Mangleburg ve Bristol 1998: 165-175) ve ürünü ya da reklam öğelerini temel alan araştırmalar (Campbell 1995: 225-254; Ritchie ve Darke, 2000; Ford vd. 1990: 433-441) olmak üzere iki gruba ayrılmaktadır (Ergeç 2009: 172-193).

2000 li yıllarda internetin ve e-ticaretin gelişmesiyle birlikte, esneklik, kolaylık (convenience), verimlilik ve eğlence çevrimiçi ortamın sunduğu hizmet kalitesi açısından en temel olumlu örnekleri olarak karşımıza çıkarken, güvenlik riski, demode olma riski, kişiselleştirilememe ve denetim zorluğu olumsuz yönleri olarak görülmüştür (Parasuraman, 2000). Forehand and Grier (2003) eğilimsel şüphecilik (predispositional skepticism) ve durumsal şüphecilik (situational skepticism) olmak üzere iki tür tüketici şüpheciliği olduğunu belirtmiştir. Eğilimsel şüpheciler, tüm işletmelerin amaçlarına karşı genel bir eğilim olarak şüphe duyarken; durumsal şüpheciler belirli bir işletmenin amaçlarından şüphe etmektedir (Kim ve Lee, 2009). Ford vd. (1990), tüketicilerin reklam önerilerini deneyimlerine göre sürekli olarak değerlendirdiklerini ve gerçekleri saklayanlardan tekrar satın alma yapmayarak geri çekilme davranışı göstereceklerini belirtmiştir. Hatta bu nedenle, reklam verenlerin davranışlarının, tüketicilerin davranışlarından etkileneceğini ifade etmiştir. Araştırmacıya göre, ürün kategorisinde uzman ya da deneyimli olan tüketiciler reklam iddialarının gerçekliğini daha doğru belirleyebilmektedir. Daha açık olmak gerekirse, ürün kategorisinde deneyimli olan tüketici geçmiş deneyimlerinde algıladığı ürün kalitesine bağgl olarak, reklam iddialarında yer verilen önerilerin ne kadar doğru ya da ne kadar yanıltıcı olduğuna daha kolay karar verebilmektedir. Buna bağlı olarak, düşük hizmet kalitesi deneyimi, aynı markanın reklamlarına yönelik şüphe eğilimini arttırabilir. Bu nedenle;

H6: Bankacılık hizmetleri kapsamında, genç tüketicilerin ürün/hizmet kalitesi algısının, reklama yönelik şüphe eğilimi üzerinde doğrudan bir etkisi vardır. 


\subsection{Bilginin Yetkisiz İkincil Kullanımı ile Ürün Kalite Algısının Seri Aracılık Etkisi}

Yukarıda bahsedilen araştırma bulgularına göre, (potansiyel) tüketicilerin kişisel bilgilerinin toplanması sonucunda oluşabilecek reklama yönelik şüphecilik eğiliminin, bu bilgilerin yetkisiz ikincil kullanımı sonucu artabileceği ancak aynı zamanda algılanan ürün kalitesinin yüksekliğine göre bu etkinin baskılanabileceği düşünülmektedir. Sonuçta, belirli bir amaç için toplanan bilgiler, kişinin bilgisi veya izni olmadan ilgisiz amaçlar için tekrar kullanılabiliyor ise (Culnan 1993, Foxman ve Kilcoyne 1993, Goodwin 1991, Smith vd. 1996; Wang vd., 1998; Culnan ve Armstrong, 1999), güvenlik ve gizliliğe ilişkin algılamalar e-hizmet kalitesini etkiliyorsa (Zeithaml vd., 2000) ve tüketiciler geçmiş deneyimlerinde algıladığı ürün kalitesine bağlı olarak, reklam iddialarında yer verilen önerilerin ne kadar doğru ya da ne kadar yanıltıcı olduğunu değerlendiriyorsa (Ford vd., 1990), bu değişkenler arasında daha karmaşık bir etkileşim olduğu varsayılabilir. Buna göre:

H7: Bankacılık hizmetleri kapsamında genç tüketicilerin kişisel bilgilerinin toplanması ile reklama yönelik şüphe eğilimleri arasındaki ilişkide, bu bilgilerin yetkisiz ikincil kullanımı ile ürün kalite algısının seri aracılık etkisi vardır.

\section{Yöntem}

$\mathrm{Bu}$ araştırmanın amacı, genç tüketiciler açısından bilgi toplama ile reklam şüpheciliği arasındaki ilişkinin ve bu ilişki kapsamında yetkisiz ikincil bilgi kullanımı ve ürün kalitesi algısının seri aracılık etkisini test etmektir. Literatür taraması sonucunda araştırmanın amacına uygun olarak oluşturulan model Şekil 1'de gösterilmiştir.

Westin'in (1967, 2003), Altman'ın (1976) ve Laufer ve Wolfe'un (1977) geliştirdiği teoriler bu alanda en s1k kullanılan çerçeveleri ortaya koymaktadır. Westin'in (2003) teorisine göre gizlilik kavramı için en önemli olgular bireylerin kişisel bilgilerinin ne zaman, nasıl ve ne bağlamda başkaları ile paylaşılacağıdır. Altman (1976), Westin'in (2003) teorisine benzer olarak, gizlilik kavramını bir kontrol mekanizması olarak ele alsa da; gizliliğin kişiler ve gruplar arasındaki bağlantılarla ilişkili kişilerarası durum olarak ele almaktadır. Laufer ve Wolfe (1977) ise bazı insanların bilgiye erişememesi durumunda, bilginin kontrol edilmesine yönelik girişimlerin söz konusu olabileceğini öne sürmüştür. Açıklanmamış veya gizli tutulmuş bilgilerin neden olacağı bilinçli ve bilinçsiz korkuların kişiliğe ve toplumsal yapıya özgü olması nedeniyle, gizliliğin korunması gerektiğini savunmuştur.

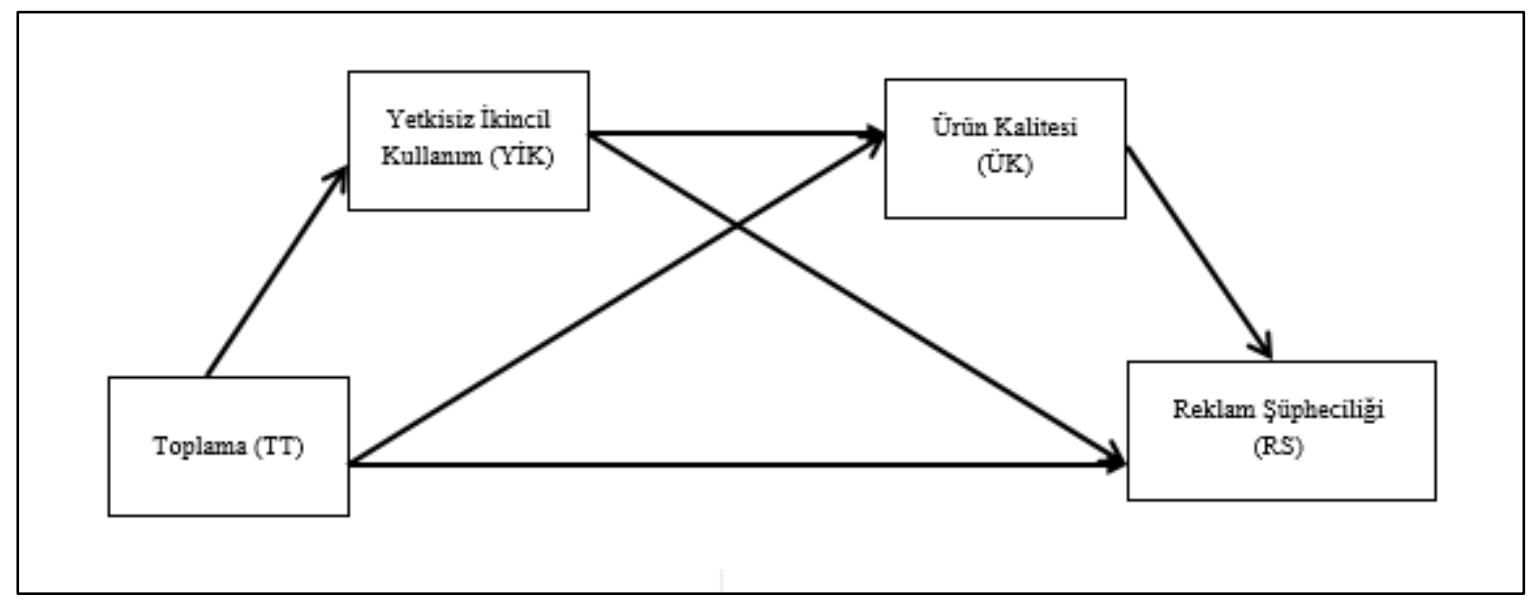

Şekil 1. Araştırma Modeli

Araştırmada yatırım bankaları özellikle tüketiciler ile birebir çalışmadıkları için kapsam dışı bırakılmıştır. Türkiye sınırları içerisinde bireysel bankacılık hizmetleri sunan 10 bankanın 2018 yılı net kâr tutarları tespit edildikten sonra, her bir bankanın yaklaşık pazar payı hesaplanmıştır. Albaraka Türk Katılım Bankası'nın (\% 1,23) ve Şekerbank'ın (\% 0,36) pazar paylarının çok düşük olduğu tespit edilmiştir. Bunun sonucunda, bu bankaların araştırma dışına çıkartılmasının örneklemin evreni temsil yeteneğini zayıflatmayacağı kanaatine varılmıştır. Katılımcıların bilgilerinin toplanabilmesi için Demografik Bilgiler, Bilgi Gizliliği, Reklam Şüpheciliği ve Kurumsal İtibar başlıklarına sahip, dört bölümden oluşan anket formu kullanılmıştır.

Bilgi toplama ve yetkisiz ikincil bilgi kullanımı hakkındaki algıyı ortaya koyabilmek için, Smith, Milberg ve Burke (1996) tarafından geliştirilmiş Bilgi Gizliliği Ölçeği kullanılmıştır. Bu ölçek Toplama, Hatalar, Uygunsuz Giriş ve Yetkisiz İkincil Kullanım olmak üzere dört boyuttan ve 15 maddeden (beşli likert tipi) oluşmaktadır. Stewart ve Segars (2002), 355 kişilik bir örneklem üzerinde yaptıkları araştırma sonrasında, bu ölçeğin psikometrik özelliklerini onaylamıştır. Bu ölçeğin tüm maddeleri öncelikli olarak Türkçe’ye çevrilmiş, Dil Bilim ve İngiliz Dili ve Edebiyatı bilim dallarında uzman akademisyenler ile görüşülerek kontrol edilmiştir. Ancak anket sorularına Hatalar ve Uygunsuz Giriş boyutuna ilişkin maddeler gerek görülmediği için alınmamıştır.

Ürün/hizmet kalitesine yönelik algının değerlendirilmesi için, Walsh ve Beatty (2007) tarafindan geliştirilmiş Müşteri Odaklı Kurumsal İtibar Ölçeği (5'li Likert) kullanılmıştır. Bu ölçek, Müşteri Odaklılık, İyi İşveren, Güvenilir ve Finansal Açıdan Güçlü İşletme, Ürün Kalitesi ile Sosyal ve Çevresel Sorumluluk olmak üzere beş alt boyutundan oluşmaktadır. Araştırma modelinin testi için Ürün Kalitesi alt boyutuna ait ifadeler kullanılmıştır. 
Reklama yönelik şüphe kapsamında ise, Obbermiller ve Spagenberg (1998) tarafından geliştirilmiş Reklama Yönelik Şüphecilik Ölçeği kullanılmıştır. Bu ölçek 9 maddeden (beşli likert tipi) oluşan tek boyutlu bir ölçektir. Bu ölçeğin tüm maddeleri öncelikli olarak Türkçe'ye çevrilmiş, Dil Bilim ve İngiliz Dili ve Edebiyatı bilim dallarında uzman akademisyenler ile görüşülerek kontrol edilmiştir. Ayrıca ölçeği Türkçe’ye uyarlayan Şahin vd.'nin (2016) ifadeleri ile de karşılaştırılmış, ifadelerin aynı olduğu belirlenmiştir. Ancak ifadelerin içeriğine bakıldığında, ölçeğin genel anlamda reklama güveni yansıttığı dolayısıyla, elde edilecek düşük ortalamanın reklama yönelik şüphenin yüksekliğini göstereceği, elde edilen yüksek ortalamanın ise reklama yönelik şüphenin düşüklüğünü ifade edeceği anlaşılmıştır.

Araştırma örneklemi, çoğunlukla 18-25 yaş aralığında en düşük üniversite eğitimi olan genç tüketiciler olarak belirlenmiştir. Çünkü bankacılık hizmetleri üzerine literatür incelendiğinde, bu tüketici grubunun nüfus içindeki yoğunluğunun yüksek olması ve farklı tüketim davranışlarına sahip olmaları nedeniyle örneklemlerin buna göre yapılandırılması önerilmiştir (Foscht vd., 2009). Bu grup özellikle teknolojiyle iç içe bir hayat yaşadıkları için, bankacılık hizmetlerinde dijital bankacılık uygulamalarını yoğunlukla kullanmaktadır (Heaney, 2007). Dolayısıyla kişisel bilgilerinin dijital formatta paylaşılması konusunda da daha fazla deneyime sahiptirler. Araştırma kapsamında, 30 Nisan30 Mayıs 2019 tarihleri arasında, internet ve basılı form üzerinden 1157 anket doldurulmuştur. Katılımcılara kolayda ve kartopu örnekleme yöntemleri ile ulaşılmıştır. Araştırma örnekleminin demografik özellikleri Tablo 1'de gösterilmiştir. Araștırmaya katılan deneklerin; \%50,7'si kadın ( $\mathrm{N}=587)$; \%49,3'ü erkektir $(\mathrm{N}=570)$. \%67,2'si 18-25 yaş aralığında $(\mathrm{N}=777)$; \%70,8'i lisans mezunu ( $=819)$; \%45,5'i 2.021-5.000 TL gelir aralığındadır (N=526). Deneklerin hizmet aldıkları bankaların, \%15,5'i T.C. Ziraat Bankası (N=179); \%15'i İş Bankası (N=173); \%14,6'sı Vakıfbank (N=169); \%11,8'i Akbank (N=137); \%11,2 ile Garanti Bankası ve Yapı Kredi Bankası (N=130); \% 7,6'sı Halkbank (N=88); \% 7,4'ü Denizbank $(\mathrm{N}=86)$; \%5,4'ü QNB Finansbank $(\mathrm{N}=63)$ ve \%0,2'si de TEB $(\mathrm{N}=2)$ 'dır.

Tablo 1. Demografik Özellikler

\begin{tabular}{|c|c|c|c|c|c|c|c|}
\hline \multicolumn{2}{|c|}{ Demografik Özellikler } & Frekans & Yüzde & \multicolumn{2}{|c|}{ Demografik Özellikler } & Frekans & Yüzde \\
\hline \multirow{4}{*}{ Cinsiyet } & Kadın & 587 & 50,7 & \multirow{8}{*}{ Gelir } & 2.020 ve alt & 87 & 7,5 \\
\hline & Erkek & 570 & 49,3 & & $2.021-5.000$ & 526 & 45,5 \\
\hline & Tonlam & 1157 & 100 & & $5.001-7.500$ & 199 & 17,2 \\
\hline & 10pum & & & & $7.501-10.000$ & 215 & 18,6 \\
\hline \multirow{8}{*}{ Yaş } & $18-25$ & 777 & 67,2 & & $10.001-12.500$ & 43 & 3,7 \\
\hline & $26-32$ & 131 & 11,3 & & $12.501-15.000$ & 37 & 3,2 \\
\hline & $33-42$ & 87 & 7,5 & & 15.000 ve üzeri & 50 & 4,3 \\
\hline & $43-50$ & 73 & 6,3 & & Toplam & 1.157 & 100 \\
\hline & $51-65$ & 82 & 7,1 & \multirow{11}{*}{$\begin{array}{l}\text { Hizmet } \\
\text { Alinan } \\
\text { Banka }\end{array}$} & T.C. Ziraat Bankasl & 179 & 15,5 \\
\hline & 66 ve üzeri & 7 & 0,6 & & $\dot{I}_{\text {Ş Bankası }}$ & 173 & 15,0 \\
\hline & & & & & Vakıfbank & 169 & 14,6 \\
\hline & Toplam & 1.157 & 100 & & Akbank & 137 & 11,8 \\
\hline \multirow{7}{*}{$\begin{array}{l}\text { Ë̆itim } \\
\text { Düzeyi }\end{array}$} & Lise & 217 & 18,8 & & Garanti Bankası BBVA & 130 & 11,2 \\
\hline & Ön Lisans & 58 & 5,0 & & Yapı Kredi Bankası & 130 & 11,2 \\
\hline & Lisans & 819 & 70,8 & & Halkbank & 88 & 7,6 \\
\hline & Yüksek Lisans & 53 & 4,6 & & Denizbank & 86 & 7,4 \\
\hline & Doktora & 10 & 0,9 & & QNB Finansbank & 63 & 5,4 \\
\hline & \multirow{2}{*}{ Toplam } & \multirow{2}{*}{1.157} & \multirow{2}{*}{100} & & $T E B$ & 2 & 0,2 \\
\hline & & & & & Toplam & 1.157 & 100 \\
\hline
\end{tabular}

\section{Yöntem}

Araştırma bulguları kullanılan ölçeklerin geçerlilik ve güvenilirlik analizleri, tanımlayıcı istatistikler, araştırma modelinin testi ve sonuçları alt başlıkları ile sunulmaktadır.

\section{1. Ölçeklerin Geçerlik ve Güvenirlik Analizleri}

Araştırma modelinin analizinden önce araştırmada yer alan yapıların geçerlik ve güvenirlik çalışmaları gerçekleştirilmiştir. Geçerlik ve güvenirlik çalışmaları kapsamında; iç tutarlılık güvenirliği (internal consistency reliability), birleşme geçerliği (convergent validity) ve ayrışma geçerliği (discriminant validity) değerlendirilmiştir. İç tutarlılık güvenirliği için Cronbach Alfa ve birleşik güvenirlik (CR=Composite Reliability) katsayıları incelenmiştir. Birleşme geçerliğinin tespitinde, faktör yükleri ile açıklanan ortalama varyans (AVE=Average Variance Extracted) değerleri kullanılmıştır. Faktör yüklerinin $\geq 0,70$; Cronbach Alpha ve birleşik güvenirlik katsayılarının $\geq 0,70$; açıklanan ortalama varyans değerinin de $\geq 0,50$ olarak gerçekleşmesi beklenmektedir (Hair vd., 2006; Hair vd., 2014; Fornell ve Larcker, 1981). Aşağıda yer alan Tablo 2'de araştırmada yer alan yapıların iç tutarlılık güvenirliği ve birleşme geçerliği ile ilgili sonuçlar yer almaktadır. 
Yıldız, E., Bozoklu, Ç., P. / Journal of Yasar University, 2019, 14 (Special Issue), 34-45

Tablo 2. Ölçüm Modeli Sonuçları

\begin{tabular}{|c|c|c|c|c|c|}
\hline Değişken & Ifade & Faktör Yükü & Cronbach Alfa & $C R$ & $A V E$ \\
\hline \multirow{4}{*}{ Toplama $(T T)$} & $T T 1$ & 0,845 & \multirow{4}{*}{0,915} & \multirow{4}{*}{0,940} & \multirow{4}{*}{0,795} \\
\hline & $T T 2$ & 0,901 & & & \\
\hline & TT3 & 0,918 & & & \\
\hline & $T T 4$ & 0,902 & & & \\
\hline \multirow{4}{*}{$\begin{array}{c}\text { Yetkisiz İkincil Kullanım } \\
\text { (YİK) }\end{array}$} & YIKI & 0,857 & \multirow{4}{*}{0,912} & \multirow{4}{*}{0,938} & \multirow{4}{*}{0,792} \\
\hline & $Y \dot{I} K 2$ & 0,895 & & & \\
\hline & $Y \dot{I K} 3$ & 0,899 & & & \\
\hline & YIK4 & 0,908 & & & \\
\hline \multirow{4}{*}{ 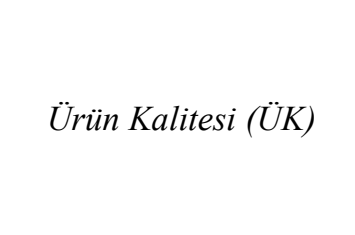 } & $\ddot{U} K 1$ & 0,901 & \multirow{4}{*}{0,927} & \multirow{4}{*}{0,948} & \multirow{4}{*}{0,819} \\
\hline & $\ddot{U} K 2$ & 0,896 & & & \\
\hline & $\ddot{U} K 3$ & 0,922 & & & \\
\hline & $\ddot{U} K 4$ & 0,901 & & & \\
\hline \multirow{9}{*}{ Reklam Şüpheciliği (RŞ) } & $R S ̧ 1$ & 0,798 & \multirow{9}{*}{0,934} & \multirow{9}{*}{0,944} & \multirow{9}{*}{0,654} \\
\hline & $R S ̧ 2$ & 0,737 & & & \\
\hline & $R S ̧ 3$ & 0,801 & & & \\
\hline & $R S ̧ 4$ & 0,856 & & & \\
\hline & $R S ̧ 5$ & 0,854 & & & \\
\hline & $R S ̧ 6$ & 0,790 & & & \\
\hline & $R S ̧ 7$ & 0,798 & & & \\
\hline & $R S ̧ 8$ & 0,861 & & & \\
\hline & $R S ̧ 9$ & 0,776 & & & \\
\hline
\end{tabular}

Yapıların, Cronbach Alfa katsayılarının 0,912 ile 0,934 arasında; CR katsayılarının da 0,938 ile 0,948 arasında gerçekleşmiş olması nedeniyle iç tutarlılık güvenirliğinin sağlandığı; faktör yüklerinin 0,737 ile 0,922 arasında; AVE değerlerinin de 0,654 ile 0,819 arasında olması nedeniyle de birleşme geçerliğinin sağlandığı görülmektedir.

Ayrışma geçerliğinin tespitinde, Fornell ve Larcker (1981) tarafindan önerilen kriter ile Henseler vd. (2015) tarafından önerilen HTMT (Heterotrait-Monotrait Ratio) kriterleri kullanılmıştır. Fornell ve Larcker (1981) kriterine göre, araştırmada yer alan yapıların ortalama açıklanan varyans (AVE) değerlerinin karekökü, araştırmada yer alan yapılar arasındaki korelasyonlardan yüksek olmalıdır. Tablo 3 'te Fornell ve Larcker (1981) kriterine göre yapılan analiz sonuçları yer almaktadır. Tablodaki değerler incelendiğinde her bir yapının ortalama açıklanan varyans değeri karekökünün diğer yapılarla korelasyonundan daha yüksek olduğu görülmektedir. Henseler vd. (2015)'nin kriterine göre HTMT, araştırmada yer alan tüm değişkenlere ait ifadelerin korelasyonlarının ortalamasının (the heterotrait-heteromethod correlations) aynı değişkene ait ifadelerin korelasyonlarının (the monotrait-heteromethod correlations) geometrik ortalamalara oranlarını ifade etmektedir. Yazarlar HTMT değerinin; 0,90'nın, içerik olarak birbirine uzak kavramlarda ise 0,85 'in altında olmasını gerektiğini belirtmişlerdir. Tablo 4'te görüldüğü gibi HTMT değerlerinin eşik değerin altındadır. Tablo 3 ve Tablo 4'teki bulgulara dayanarak ayrışma geçerliğinin sağlandığı belirtilebilir.

Tablo 3. Ayrışma Geçerliği Sonuçları (Fornell ve Larckell Kriteri)

\begin{tabular}{|c|c|c|c|c|}
\hline & $\begin{array}{c}\text { Reklam } \\
\text { Şüpheciliği }\end{array}$ & Toplama & $\begin{array}{c}\text { Yetkisiz Ikincil } \\
\text { Kullanım }\end{array}$ & Ürün Kalitesi \\
\hline Reklam Şüpheciliği & $(0,809)$ & & & \\
\hline Toplama & $-0,111$ & $(0,892)$ & & \\
\hline $\begin{array}{l}\text { Yetkisiz Íkincil } \\
\text { Kullanım }\end{array}$ & $-0,154$ & 0,253 & $(0,890)$ & \\
\hline Ürün Kalitesi & 0,282 & $-0,066$ & 0,153 & $(0,905)$ \\
\hline
\end{tabular}


Yıldız, E., Bozoklu, Ç., P. / Journal of Yasar University, 2019, 14 (Special Issue), 34-45

Tablo 4. Ayrışma Geçerliği Sonuçları (Henseler vd. Kriteri)

\begin{tabular}{|l|c|c|c|c|}
\hline & $\begin{array}{c}\text { Reklam } \\
\text { Şüpheciliği }\end{array}$ & Toplama & $\begin{array}{c}\text { Yetkisiz İkincil } \\
\text { Kullanım }\end{array}$ & Ürün Kalitesi \\
\hline Reklam Şüpheciliği & 0,116 & & & \\
\hline Toplama & 0,164 & 0,271 & & \\
\hline $\begin{array}{l}\text { Yetkisiz Íkincil } \\
\text { Kullanım }\end{array}$ & 0,303 & 0,074 & 0,164 & \\
\hline Ürün Kalitesi & & & & \\
\hline
\end{tabular}

\subsection{Tanımlayıcı İstatistikler}

Tablo 5'te tanımlayıcı istatistikler sunulmuştur. Katılımcıların algıları, en yüksek ortalama ile yetkisiz ikincil kullanım değişkeninde (Ort.=4,73); en düşük ortalama ise reklam şüpheciliği değişkeninde $($ Ort.=2,34) gerçekleşmiştir. Yöntem kısmında da belirtildiği gibi, ifadelerin içeriği nedeniyle, düşük olarak hesaplanan ortalama aslında genç tüketicilerin reklama yönelik şüphe eğilimlerinin yüksek olduğunu göstermektedir. Dolayısıyla, katılımcıların kişisel bilgilerinin toplanmasına, bu bilgilerin ikincil kullanımına yönelik endişeleri ile reklama yönelik şüphe eğilimleri yüksek olmasına karşın, tercih ettikleri bankaların sunduğu ürünlere yönelik kalite algıları da oldukça olumludur.

Tablo 5. Tanımlayıcı İstatistikler

\begin{tabular}{|l|c|c|c|}
\hline \multicolumn{1}{|c|}{ Değişkenler } & Ortalama & Standart Sapma \\
\hline Toplama & & 3,68 & 1,13 \\
\hline Yetkisiz İkincil Kullanım & & 4,73 & 0,64 \\
\hline Ürün Kalitesi & & 3,74 & 0,92 \\
\hline Reklam Şüpheciliği & 2,34 & 0,88 \\
\hline
\end{tabular}

\subsection{Araştırma Modelinin Test Edilmesi ve Sonuçları}

Araştırmanın hipotezlerini test etmek amacıyla oluşturulan yapısal eşitlik modeli Şekil 2'de gösterilmiştir.

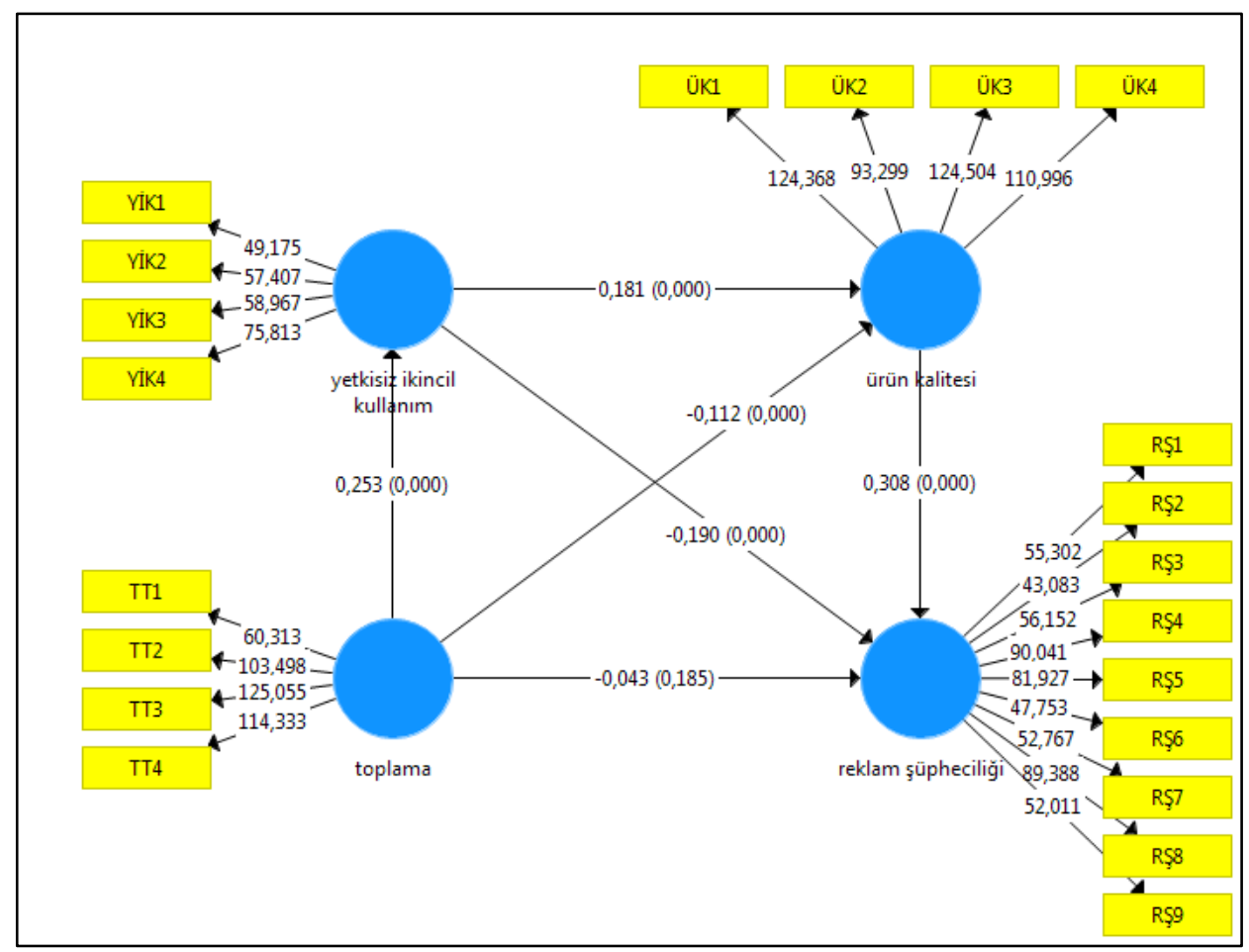

Şekil 2. Yapısal Eşitlik Modeli 
Araştırma modelinin analiz edilmesinde kısmi en küçük kareler yol analizi (PLS-SEM) kullanılmıştır. Veriler SmartPLS 3.2.8 istatistik programı kullanılarak analiz edilmiştir (Ringle vd., 2015). Araştırma modeline ilişkin; doğrusallık, yol katsayıları, R2 ve etki büyüklüğünü (f2') hesaplamak için PLS algoritması; tahmin gücünü (Q2)' hesaplamak için de Blindfolding analizi çalıştırılmıştır. PLS yol katsayılarının anlamlılıklarını değerlendirmek için yeniden örnekleme (bootstrapping) ile örneklemden 5000 alt örneklem alınarak t-değerleri hesaplanmıştır. Araştırma sonuçlarına ilişkin R2, f2, Q2 ve VIF değerleri Tablo 6'da sunulmuştur. Değişkenler arasındaki VIF (Variance Inflation Factor) değerleri incelendiğinde, değerlerin eşik değer olan 5'in altında olması nedeniyle değişkenler arasında doğrusallık problemi olmadığı anlaşılmıştır (Hair vd., 2014). Modele ait elde edilen R2 değerleri incelendiğinde de yetkisiz ikincil kullanımın $\% 6$, ürün kalitesinin $\% 4$ ve reklam şüpheciliğinin de $\% 12$ oranında açıklandığ 1 tespit edilmiştir. Etki büyüklüğü katsayısının (f2) 0,02 ve üzeri olması düşük; 0,15 ve üzeri olması orta; 0,35 ve üzeri olması ise yüksek olarak değerlendirilmektedir (Cohen, 1988). Sarstedt vd. (2017)'e göre de katsayının 0,02'nin altında geçekleştiği durumlarda da bir etkiden söz etmenin mümkün olmadığı belirtilmiştir. Etki büyüklüğü katsayıları (f2) incelendiğinde; toplamanın yetkisiz ikincil kullanım üzerinde, yetkisiz ikincil kullanımın ürün kalitesi üzerinde, yetkisiz ikincil kullanım ve ürün kalitesinin reklam şüpheciliği üzerinde düşük seviyede etki büyüklüğüne sahip olduğu görülmüştür. Aynı zamanda toplamanın ürün kalitesi ve reklam şüpheciliği üzerindeki etkilere yönelik katsayıların 0,02'nin altında olduğu tespit edilmiştir. Model üzerinde yapılan incelemede katsayıların düşüklüğünün dolaylı etkilerden kaynaklığı anlaşılmıștır. Endojen değişkenler için hesaplanan tahmin gücü katsayılarının (Q2) sıfırdan büyük olması, araştırma modelinin, endojen değişkenleri tahmin gücüne sahip olduğunu göstermektedir (Hair vd., 2014). Tablodaki Q2 değerlerinin sifirdan büyük olması nedeniyle araştırma modelinin yetkisiz ikincil kullanım, ürün kalitesi ve reklam şüpheciliği değişkenlerini tahmin gücüne sahip olduğu belirtilebilir.

Tablo 6. Araştırma Modeli Katsayıları (Toplam Etki)

\begin{tabular}{|c|c|c|c|c|}
\hline Değişkenler & $V I F$ & $R^{2}$ & $f^{2}$ & $Q^{2}$ \\
\hline Toplama $\rightarrow$ Yetkisiz Íkincil Kullanım & 1,000 & 0,064 & 0,069 & 0,047 \\
\hline Toplama $\rightarrow$ Ürün Kalitesi & 1,069 & \multirow{2}{*}{0,035} & 0,012 & \multirow{2}{*}{0,026} \\
\hline Yetkisiz İkincil Kullanım $\rightarrow$ Ürün Kalitesi & 1,069 & & 0,032 & \\
\hline Toplama $\rightarrow$ Reklam Şüpheciliği & 1,082 & \multirow{3}{*}{0,121} & 0,002 & \multirow{3}{*}{0,073} \\
\hline Yetkisiz İkincil Kullanım $\rightarrow$ Reklam Şüpheciliği & 1,103 & & 0,037 & \\
\hline Ürün Kalitesi $\rightarrow$ Reklam Şüpheciliği & 1,036 & & 0,104 & \\
\hline
\end{tabular}

Araştırma modeline ilişkin etkilere yönelik sonuçlara Tablo 7'de yer verilmiştir. Toplamanın reklam şüpheciliği üzerindeki toplam etkisini hesaplamak için modelden aracı değişkenler çıkarılarak model test edilmiştir. Test sonucunda toplamanın reklam şüpheciliğini $(\beta=-0,119 ; p<0,01)$ etkilediği tespit edilmiştir. Bu sonuca dayanarak araştırmanın H4 desteklenmiştir. İkinci aşamada aracı değişkenler modele dahil edilerek yol katsayılarının anlamlılı̆gı test edilmiştir. Yetkisiz ikincil kullanımın reklam şüpheciliğini $(\beta=-0,190 ; p<0,01)$; ürün kalitesinin reklam şüpheciliğini $(\beta=0,308$; $\mathrm{p}<0,01)$; toplamanın yetkisiz ikincil kullanımı $(\beta=0,253 ; \mathrm{p}<0,01)$; toplamanın ürün kalitesini $(\beta=-0,112 ; \mathrm{p}<0,01)$ ve yetkisiz ikincil kullanımın ürün kalitesini $(\beta=0,181 ; p<0,01)$ etkilediği gözlemlenmiştir. Bu bulgular 1şı̆̆ında H1, H2, H3, H5 ve H6 kabul edilmiştir.

Tablo 7. Araştırma Modeli Etki Katsayıları (Dolaylı Etki)

\begin{tabular}{|c|c|c|c|c|c|}
\hline Değişkenler & $\begin{array}{c}\text { Standardize } \\
\beta\end{array}$ & $\begin{array}{c}\text { Standart } \\
\text { Hata }\end{array}$ & t değeri & $p$ & $\begin{array}{c}\text { \%95 Güven } \\
\text { Aralığl }\end{array}$ \\
\hline Toplama $\rightarrow$ Reklam Şüpheciliği & $-0,119$ & 0,027 & 4,420 & 0,000 & $-0,166 ;-0,067$ \\
\hline Yetkisiz Íkincil Kullanım $\rightarrow$ Reklam Şüpheciliği & $-0,190$ & 0,034 & 5,555 & 0,000 & $-0,253 ;-0,120$ \\
\hline Ürün Kalitesi $\rightarrow$ Reklam Şüpheciliği & 0,308 & 0,028 & 10,856 & 0,000 & 0,$248 ; 0,360$ \\
\hline Toplama $\rightarrow$ Yetkisiz İkincil Kullanım & 0,253 & 0,029 & 8,641 & 0,000 & 0,$194 ; 0,307$ \\
\hline Toplama $\rightarrow \ddot{U}$ rün Kalitesi & $-0,112$ & 0,031 & 3,619 & 0,000 & $-0,170 ;-0,051$ \\
\hline 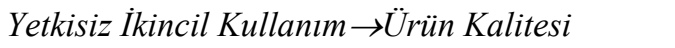 & 0,181 & 0,036 & 5,099 & 0,000 & 0,$110 ; 0,251$ \\
\hline
\end{tabular}

Seri aracılık etkisine yönelik sonuçlar Tablo 8'de sunulmuştur. Tablodaki bulgular incelendiğinde toplama ile reklam şüpheciliği arasındaki ilişkide toplam dolaylı etkinin anlamlı olduğu anlaşılmıştır $(\beta=-0,069 ; p<0,01)$. Ayrıca tablodaki bulgular doğrultusunda toplam dolaylı etkiyi oluşturan 3 ayrı dolaylı etkinin de anlamlı olduğu tespit edilmiştir. Dolaylı etkilerin tespit edilmiş olması nedeniyle toplam dolaylı etkiye yönelik VAF (Variance Accounted For) katsayısı hesaplanmıştır (Doğan, 2018). Hesaplanan VAF katsayısının 0,37 olması nedeniyle toplama ile reklam şüpheciliği 
arasındaki ilişkide yetkisiz ikincil kullanım ve ürün kalitesinin kısmi aracılık rolü olduğu ifade edilebilir. Dolayısıyla H7 kabul edilmiştir.

Tablo 8. Aracılık ve Seri Aracılık Etki Katsayıları

\begin{tabular}{|c|c|c|c|c|c|}
\hline Değişkenler & Standardize $\beta$ & $\begin{array}{c}\text { Standart } \\
\text { Hata }\end{array}$ & $t$ değgeri & $p$ & 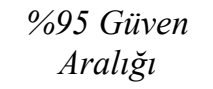 \\
\hline$T T \rightarrow R S ̧$ (Toplam Dolaylı Etki) & $-0,069$ & 0,014 & 4,958 & 0,000 & $-0,096 ;-0,042$ \\
\hline$T T \rightarrow Y \dot{I} K \rightarrow R S$ & $-0,048$ & 0,011 & 4,512 & 0,000 & $-0,071 ;-0,029$ \\
\hline$T T \rightarrow \ddot{U} K \rightarrow R S$ & $-0,035$ & 0,010 & 3,306 & 0,001 & $-0,056 ;-0,015$ \\
\hline$T T \rightarrow Y \dot{I} K \rightarrow \ddot{U} K \rightarrow R S ̧$ & 0,014 & 0,004 & 3,233 & 0,001 & 0,$007 ; 0,024$ \\
\hline $\begin{array}{l}\text { TT: Toplama } \\
\text { YIK: Yetkisiz İkincil Kullanım } \\
\ddot{U} K: \text { Ürün Kalitesi } \\
R S ̧: \text { Reklam Şüpheciliği }\end{array}$ & & & & & \\
\hline
\end{tabular}

\section{Sonuç ve Öneriler}

Sosyal güven (social credit) teorisine göre, bir tüketici kişisel bilgilerini her hangi bir işletmeyle paylaştığında, işletme ile arasında bilgi gizliliği bağlamında uzun vadeli bir değişim ilişkisi başlamaktadır (Malhorta vd., 2004). Ancak bu sosyal sözleşme işletmelerin, gereğinden fazla ya da izinsiz bilgi toplama çabaları ile toplanan bilgileri yetkisiz olarak içerden ya da dışardan yetkisiz ikincil kullanımı sonucunda ortadan kalkmaktadır. Bu tür deneyimler yaşayan tüketicilerin farklı ticari uygulamalara da benzer şüphe ile yaklaşabileceği varsayıldığı için, bu araştırmanın temel amacı bilgi toplama ile reklam şüpheciliği eğilimi arasındaki ilişkide, bilginin yetkisiz ikincil kullanımı ve ürün kalite algısının seri aracılık etkisinin ölçülmesidir.

Elde edilen bulgulara göre, genç tüketiciler, her ne kadar kullandıkları bankaların ürün kalitesini yüksek olarak algılasalar da; kişisel bilgilerinin toplanmasına ve bu bilgilerin yetkisiz ikincil kullanımına yönelik yüksek endişelere sahiptir. Ayrıca, temel varsayımda olduğu gibi genç tüketicilerin reklamlara yönelik şüphe eğilimleri (ifadelerin içeriği nedeniyle düşük ortalama yüksek şüpheyi göstermektedir) de ortalamanın üstündedir. Yapılan model testi sonucunda, bilgi toplamanın bu toplanan bilgilerin yetkisiz ikincil kullanımına yönelik kaygıları kuvvetlendirdiği tespit edilmiştir. Bilgi toplama ile reklam şüpheciliği arasındaki ilişkide bilginin yetkisiz ikincil kullanımına yönelik kaygıların da reklam şüpheciliğini tetiklediği, ancak ürün kalitesi algısının yüksek olması nedeniyle bu etkinin bastırıldığı ortaya koyulmuştur. Ancak algılanan ürün kalitesinin düşük olması durumunda ise, şüpheciliğin daha da yükseleceği tahmin edilmektedir.

$\mathrm{Bu}$ bulgular, tüketim karşıtlığının ve tüketici sinisizminin hızla yaygınlaştığı günümüzde, yabancılaşan ve ticari uygulamalardan kaçınan tüketicilerin yeniden karşılıklı sosyal güvene dayalı olarak pazara çekilebilmesine öneriler sunduğu için oldukça önemlidir. Karşılıklı sosyal sözleşmeyi bozan ticari uygulamalar ile bu tür uygulamaların yeterince denetlenmemesi ve cezalandırılmaması sonucunda, güvensizlik ve şüphecilik yaygınlaşmaktadır. Bu tür negatif tüketici tutumlarının önüne geçebilmek ve yeniden tüketiciler ile sağlıklı uzun süreli ilişkiler kurulabilmek için işletmeler, özellikle yenilikçi yaklaşımı benimseyerek, sunduğu hizmetlerin arkasında durarak, güçlü ve güvenilir bir imaj yaratarak sundukları mal ve hizmetlerin kalitesine yatırım yapmalıdır.

$\mathrm{Bu}$ araştırma önemli bulgular sunsa da, kolayda örnekleme yönteminin kullanılmış olması ve tek bir sektöre odaklanılması bu araştırmanın kısıtlarını oluşturmaktadır. Gelecekte yürütülecek araştırmaların bilgi gizliliği kavramını daha bütüncül olarak ele alması ile işletmelerin sosyal katkılarının bu tür negatif tutumlar üzerindeki baskılayıcı etkisini ortaya koyacak modellere odaklanması yeni bakış açıları sunabilir. Kurumsal sosyal sorumluluk faaliyetlerinin etkisi ve çeşitli risk algıları eklenerek daha gelişmiş modeller ile farklı tüketici gruplarının değerlendirilmesi önerilmektedir. Özellikle şüphe gibi negatif tutum gösteren aktivist tüketiciler üzerine yoğunlaşılması, hem tüketici davranışı literatürüne katkı sağlayacak hem de ticari uygulamaların etkinliğini arttıracaktır. 


\section{KAYNAKÇA}

Altman, I. 1976. “A conceptual analysis”. Environment and Behavior, 8(1):7-29.

Baek, T. H., Morimoto, M. 2012. "Stay away from me". Journal of Advertising, 41(1):59-76.

Boush, D. M., Friestad, M., Rose, G. M. 1994. “Adolescent skepticism toward TV advertising and knowledge of advertiser tactics”. Journal of Consumer Research, 21(1):165-175.

Boush, D. M., Friestad, M., Wright, P., 2009. Deception in the Marketplace. New York: Routledge, Taylor \& Francis Group

Brehm, S. S., Brehm, J. W. 2013. Psychological reactance: A theory of freedom and control. Academic Press.

Brown, C. L., Krishna, A. 2004. "The skeptical shopper: A metacognitive account for the effects of default options on choice”. Journal of Consumer Research, 31(3):529-539.

Calo, M. R. 2011. "The drone as a privacy catalyst". Stan. L. Rev. Online, 64:29.

Campbell, M. C. 1995. "When Attention-Getting Advertising Tactics Elicit Consumer Inferences of Manipulative Intent: The Importance of Balancing Benefits and Investments". Journal of Consumer Psychology, 4(3): 225-254.

Casaló, L. V., Flavián, C., Guinalíu, M. 2007. "The role of security, privacy, usability and reputation in the development of online banking". Online Information Review, 31(5):583-603.

Cate, F. H. (2006). The failure of fair information practice principles. In J. K. Winn (Ed.), Consumer protection in the age of the information economy (pp. 343-379). Surrey: Ashgate Publishing.

Cohen, J. 1988. Statistical Power Analysis For The Behavioral Sciences. NJ: Mahwah, Lawrence Erlbaum

Culnan, M. J. 1993. "How Did They Get My Name?": An Exploratory Investigation of Consumer Attitudes toward Secondary Information Use". MIS Quarterly, 341-363.

Culnan, M. J., Armstrong, P. K. 1999. "Information privacy concerns, procedural fairness, and impersonal trust: An empirical investigation". Organization Science, 10(1):104-115.

Doğan, D. 2018. SmartPLS İle Veri Analizi. US: Charleston SC.

Donaldson, T., Dunfee, T. W. 1994. "Toward a unified conception of business ethics: Integrative social contracts theory". Academy of Management Review, 19(2):252-284.

Edwards, M. A. 2004. "Empirical and Behavioral Critiques of Mandatory Disclosure: Socio-Economics and the Quest for Truth in Lending." Cornell JL \& Pub. Pol'y, 14:199.

Elving, W. J. 2013. "Scepticism and corporate social responsibility communications: the influence of fit and reputation". Journal of Marketing Communications, 19(4):277-292.

Ergeç, E. N., 2009. "Reklama Şüpheci Yaklaşımın İncelenmesi”. Ç.Ü. Sosyal Bilimler Enstitüsü Dergisi, 18(2):172-193.

Flavia'n, C., Guinalı'u, M. 2006. "Consumer trust, perceived security, and privacy policy: three basic elements of loyalty to a web site". Industrial Management \& Data Systems., 106(5/6): 601-20.

Ford, G. T., Smith, D. B., Swasy, J. L. 1990. "Consumer skepticism of advertising claims: Testing hypotheses from economics of information". Journal of Consumer Research, 16(4):433-441.

Forehand, M. R.,Grier, S. 2003. "When is honesty the best policy? The effect of stated company intent on consumer skepticism". Journal of Consumer Psychology, 13(3):349-356.

Fornell, C., Larcker, D.F. 1981. "Evaluating Structural Equation Models With Unobservable Variables And Measurement Error". Journal of Marketing Research, 18(1):39-50.

Foscht, T., Schloffer, J., Maloles III, C., Chia, S. L. 2009. “Assessing the outcomes of Generation-Y customers' loyalty”. International Journal of Bank Marketing, 27(3):218-241.

Foxman, E. R., Kilcoyne, P. 1993. "Information technology, marketing practice, and consumer privacy: Ethical issues". Journal of Public Policy \& Marketing, 12(1):106-119.

Furnell, S. M., Karweni, T. 1999. "Security implications of electronic commerce: a survey of consumers and businesses". Internet Research, 9(5):372-382.

Goodwin, C. 1991. "Privacy: Recognition of a consumer right". Journal of Public Policy \& Marketing, 10(1):149-166.

Grönroos, C. 1984. “A service quality model and its marketing implications”. European Journal of Marketing, 18(4):3644.

Hair, J. F., Black, W. C., Babin, B. J., Anderson, R. E., Tatham, R. L. 2006. Multivariate Data Analysis. Upper Saddle River, NJ: Pearson Prentice Hall.

Hair, J.F., Tomas, G., Hult, M., Ringle, C.M., Sarstedt, M. 2014. A Primer on Partial Least Square Structural Equations Modeling (PLS-SEM). Los Angeles: Sage.

Harris, L. C., Goode, M. M. 2004. "The four levels of loyalty and the pivotal role of trust: a study of online service Dynamics". Journal of Retailing, 80(2):139-158.

Heaney, J.G. 2007. “Generations X and Y's internet banking usage in Australia”. Journal of Financial Services Marketing, 11(3):196-210.

Helm, A. E. 2006. Cynical consumers: dangerous enemies, loyal friends. (Doctoral dissertation). University of Missouri, Columbia.

Henseler, J., Ringle, C.M., Sarstedt, M. 2015. “A New Criterion For Assessing Discriminant Validity in Varience-Based Structural Equation Modelling". Journal of the Academy of Marketing Science, 43:115-135.

HEW 1973. (U.S. Department of Health, Education, and Welfare). "Records, Computers, and the Rights of Citizens: Report of the Secretary's Advisory Committee on Automated Personal Data Systems". U.S. Government Printing Office, Washington, D.C. 
Yıldız, E., Bozoklu, Ç., P. / Journal of Yasar University, 2019, 14 (Special Issue), 34-45

Hürriyet 2018. "Facebook Skandal Sonrası 70 Milyon Kaybetti!", 28.03.2018 Çevrim içi: http://www.hurriyet.com.tr/teknoloji/facebook-skandal-sonrasi-70-milyar-dolar-kaybetti-40786851, erişim tarihi: 02.07.2019.

Kim, Y. J., Lee, W. N. 2009. "Overcoming consumer skepticism in cause-related marketing: The effects of corporate social responsibility and donation size claim objectivity”. Journal of Promotion Management, 15(4):465-483.

Knowles, E. S., Linn, J. A. 2004. Resistance and persuasion. Psychology Press.

Kruck, S.E., Gottovi, D., Moghadami, F., Broom, R., Forcht, K.A. 2002. "Protecting personal privacy on the internet", Information Management \& Computer Security, 10(2): 77-84.

Laufer, R. S., Wolfe, M. 1977. "Privacy as a concept and a social issue: A multidimensional developmental theory". Journal of Social Issues, 33(3):22-42.

Li, H., Sarathy, R., Xu, H. 2010. "Understanding situational online information disclosure as a privacy calculus". Journal of Computer Information Systems, 51(1):62-71.

Li, Y. 2014. "The impact of disposition to privacy, website reputation and website familiarity on information privacy concerns". Decision support systems, 57:343-354.

Malhotra, N. K., Kim, S. S., Agarwal, J. 2004. "Internet users' information privacy concerns (IUIPC): The construct, the scale, and a causal model". Information Systems Research, 15(4):336-355.

Mangleburg, T. F., Bristol, T. 1998. "Socialization and Adolescents' Skepticism toward Advertising". Journal of Advertising, 27(3):11-21.

Mason, R. O. 1986. "Four ethical issues of the information age". Mis Quarterly, 5-12.

Milberg, S. J., Burke, S. J., Smith, H. J., Kallman, E. A. 1995. "Values, personal information privacy, and regulatory approaches". Communications of the ACM, 38(12):65-75.

Milberg, S. J., Smith, H. J., Burke, S. J. 2000. I"nformation privacy: Corporate management and national regulation". Organization Science, 11(1):35-57.

Miller, A. 1982. Computers and privacy. WM Hoffman, JM Moore, (Eds.) Ethics and the Management of Computer Technology. Oelgeschlager, Gunn.

Milne, G. R., Boza, M. E. 1999. "Trust and concern in consumers' perceptions of marketing information management practices". Journal of Interactive Marketing, 13(1):5-24.

Obermiller, C. 1998. "Development of a Scale to Measure Consumer Skepticism toward Advertising". Journal of Consumer Psychology, 7(2):159-186.

Obermiller, C., Spangenberg, E. R., 1998. "Development of a scale to measure consumer skepticism toward advertising". Journal of Consumer Psychology. 7(2):159-186.

Okazaki, S., Li, H., Hirose, M. 2009. "Consumer privacy concerns and preference for degree of regulatory control". Journal of Advertising, 38(4):63-77.

Oly Ndubisi, N., Sinti, Q. 2006. "Consumer attitudes, system's characteristics and internet banking adoption in Malaysia". Management Research News, 29(1/2):16-27.

Parasuraman, A., Zeithaml, V. A., Berry, L. L. 1985. "A conceptual model of service quality and its implications for future research". Journal of Marketing, 49(4):41-50.

Parasuraman, A., Zeithaml, V. A., Berry, L. L. 1988. "Servqual: A multiple-item scale for measuring consumer perceptions of service quality". Journal of Retailing, 64(1):12.

Parasuraman, A. 2000. “Technology Readiness Index (TRI) a multiple-item scale to measure readiness to embrace new Technologies". Journal of Service Research, 2(4):307-320.

Pew Research Center 2007. Changing faiths: Latinos and the transformation of American religion. Washington, DC: Pew Research Center.

Phelps, J. E., D'Souza, G., Nowak, G. J. 2001. “Antecedents and consequences of consumer privacy concerns: An empirical investigation". Journal of Interactive Marketing, 15(4):2-17.

Pikkarainen, T., Pikkarainen, K., Karjaluoto, H., Pahnila, S. 2004. "Consumer acceptance of online banking: an extension of the technology acceptance model”. Internet Research, 14(3):224-235.

PPSC (Privacy Protection Study Commission) 1997. Personal Privacy in an Information Society: Report of the Privacy Protection Study Commission, Washington, D.C: U.S. Government Printing Office.

Rahn, W. M., Transue, J. 1998. "Social trust and value change: The decline of social capital in American youth, 19761995". Political Psychology, 19:545-565.

Ritchie, R. J. B., Darke, P.R. 2000. "In the Shadow of Doubt:AdvertiserDeception and the Defensive Consumer". Poster Session Presented at theAssociation for Consumer Research Conference, Salt Lake City, UT.

Şahin, Ş., Yönet, Ö., Suher, H. K. 2016. "Reklama Yönelik Şüphecilik: Anne-Baba Ve Çocukları Arasındaki Farklar Üzerine Bir İnceleme". Ekurgu, 24(2):55-73.

Sai, Y. 2008. “Transparent Safe”. Decision Support Systems, 46(1):41-51.

Sarstedt, M., Ringle, C.M., Hair, J.F. 2017. "Partial Least Squares Structural Equation Modelling”, In C. Homburg, M.Klarmann, A.Vomberg (Eds.), Handbook of Market Research, Heidelberg: Springer.

Schlosser, A.E., White, T.B., Lloyd, S.M. 2006. "Converting web site visitors into buyers: how web site investment increases consumer trusting beliefs and online purchase intentions". Journal of Marketing, 70: 133-48.

Schwaig, K. S., Segars, A. H., Grover, V.,Fiedler, K. D. 2013. "A model of consumers' perceptions of the invasion of information privacy". Information \& Management, 50(1):1-12.

Smit, E. G., Van Noort, G., Voorveld, H. A. 2014. "Understanding online behavioural advertising: User knowledge, privacy concerns and online coping behaviour in Europe". Computers in Human Behavior, 32:15-22. 
Smith, H. J. 1994. Managing privacy: Information technology and corporate America. UNC Press Books.

Smith, H. J., Milberg, S. J., Burke, S. J. 1996. 'Information privacy: measuring individuals' concerns about organizational practices”. MIS Quarterly, 167-196.

Stewart, K. A., Segars, A. H. 2002. "An empirical examination of the concern for information privacy instrument". Information Systems Research, 13(1):36-49.

Stone, E. F., Gueutal, H. G., Gardner, D. G., McClure, S. 1983. "A field experiment comparing information-privacy values, beliefs, and attitudes across several types of organizations". Journal of Applied Psychology, 68(3):459.

Tolchinsky, P. D., McCuddy, M. K., Adams, J., Ganster, D. C., Woodman, R. W., Fromkin, H. L. 1981. "Employee perceptions of invasion of privacy: A field simulation experiment". Journal of Applied Psychology, 66(3):308.

Walsh, G., Beatty, S. E. 2007. "Customer-based corporate reputation of a service firm: scale development and validation". Journal of The Academy of Marketing Science, 35(1):127-143.

Wang, H., Lee, M. K., Wang, C. 1998. "Consumer privacy concerns about Internet marketing”. Communications of the ACM, 41(3):63-70.

Westin, A. F. 1967. "Privacy and freedom Atheneum". New York, 7, 431-453.

Westin, A. F., Baker, M. A. 1972. Databanks in a Free Society. New York: Quadrangle Books.

Westin, A. F. 2003. "Social and political dimensions of privacy". Journal of Social Issues, 59(2):431-453.

White, T. B., Zahay, D. L., Thorbjørnsen, H., Shavitt, S. 2008.” Getting too personal: Reactance to highly personalized email solicitations". Marketing Letters, 19(1):39-50.

Xu, H., Dinev, T., Smith, J., Hart, P. 2011. "Information privacy concerns: Linking individual perceptions with institutional privacy assurances". Journal of the Association for Information Systems, 12(12):1.

Yang, Z. 2001. "Consumer perceptions of service quality in Internet-based electronic commerce". In Proceedings of the EMAC Conference (Vol. 811, May).

Zeithaml, V. A., Parasuraman, A., Malhotra, A. 2000. A conceptual framework for understanding e-service quality: implications for future research and managerial practice. Marketing Science Institute. 